\section{Defining consciousness}

SIR - We are pleased to learn ${ }^{1}$ that the convention that "consciousness is so illdefined that it lies beyond the reach of serious study' is losing ground. Something is still missing from the studies reported by Jeffrey Gray, however, especially an acknowledgement of the fact that consciousness has more subtle aspects than examples such as 'red', 'pain' and 'itch', and more importantly that it can be studied from within.

We know, for example, about belief and hope because we believe and hope ourselves, and are aware of the fact that we do so. Such attributions are traditionally called by psychologists 'fictions' (as opposed to the 'facts' discovered by science).

But this fact/fiction duality is a false one $^{2}$ : modern physics, for example, posits many entities that through their unobservability may be considered just as much fiction as fact, and hopes and beliefs are just as much fact as fiction.

The same, we believe, can be said of more delicate aspects of experience such as those pertaining to the arts, or spiritual experience. Such experiences, to the extent that they are capable (as is frequently the case) of being put into words understood by others, can become knowledge and understanding that, like scientific knowledge, can be discussed in depth and become ultimately the shared, usable knowledge of an expert community.

Science's insistence upon the fact/ fiction dichotomy referred to (in common with other ultimately spurious distinctions, such as the supposed sharp distinction between science and philosophy) is the outcome of the way scientists are trained to think: to see only certain forms of observation, certain forms of argument and certain categories of description as being 'correct'.

Such constraints, while indispensable as a tool for carrying out science as at present conceived, create a limited perspective upon reality as a whole, denying, for example, the real existence of meaning and value, and (assuming that the following fiction-word has meaning!) devaluing introspective investigations into (to take a particular example) the problem of personal identity ("who - or what - am I?') $)^{3,4}$. The question 'what is it like to be a human being?' should, for human beings, be easier to answer, and more relevant to human needs, than Nagel's question 'what is it like to be a bat?'

What we have argued about entails what we see as a necessary revision in the way the problem of consciousness is viewed, involving the adoption of a vantage point from which knowledge is viewed as a unified whole, of which scientific knowledge is but one aspect.

Brlan D. Josephson

Department of Physics,

University of Cambridge,

Madingley Road, Cambridge CB3 OHE, UK

Beverly A. Rubik

Centre for Frontier Sciences,

Ritter Hall 003-00,

Temple University,

Philadelphia, Pennsylvania 19122, USA

David Fontana

School of Education,

University of Wales,

21 Senghenydd Road,

Cardiff CF2 $4 A G$, UK

David Lorimer

Scientific and Medical Network,

Garden Cottage, Newhouse Farm,

Northington Down,

Alresford, Hants SO214 9UB, UK

1. Gray, J. Nature 358, 277 (1992).

2. Merleau-Ponty, M. The Visible and the Invisible (Northwestern University Press, Evanston, 1968).

3. Shear, J. The Inner Dimension (Peter Lang Publishing

Inc. New York, Bern, Frankfurt am Main and Paris 1990).

4. Zohar, D. The Quantum Self (Bloomsbury, London, 1990)

SIR - Jeffrey Gray's fascinating article ends on a tantalizing note. One needs more than the gathering of experimental data, he concludes - one needs " . . . a new theory .... that will render the relations between brain events and conscious experience 'transparent' ... . This new theory is at present unimaginable

Such a theory may indeed need to be profoundly different from any existing one if it is to transcend the limitations of neurocomputational models. But just such a theory has been imagined, and with great force and originality, by Gerald Edelman, and has been set out in detail by him in several books (most especially in The Remembered Present: A Biological Theory of Consciousness). Whether Edelman's full theory of neuronal group selection will be confirmed by rigorous testing is as yet unclear; but it represents a monumental theoretical construct, and surely deserves a mention.

\section{Oliver Sacks}

299 West 12 Street, 14C,

New York,

New York 10014, USA

\section{Frontiers future}

SIR - As one of the founders of the Human Frontier Science Program, I should like to comment on the present controversy over the future of the programme (see Nature 358, 527; 1992).

(1) Human Frontiers puts a relatively small amount of money into two areas of research: brain functions, and 'molecular approaches' to elucidation of biological functions. The money spreads to countries that already have well-funded research programmes in traditional areas of biological research. Frontiers should not seek to compete with these existing programmes. Rather, through its uniqueness it should seek to add an international component to research.

(2) Frontiers supports two selected areas, but advances in these fields will come from other areas, in particular chemistry, physics and computational science, which offer not just new techniques, but also new concepts and different approaches. The programme should foster growth of interdisciplinary research at the borders of biology.

(3) The secretary general of the programme should have a wide knowledge of science and the ability to move the programme into these areas. It is not a major administrative job, but one that requires intellectual leadership; it could be carried out on a part-time basis.

Glauco P. Tocchini-Valentini

Institute of Cell Biology,

Via Marx, 43,

0137 Roma,

Italy

\section{Motes and beams}

SIR - I agree that "there must, after all, be some standards" (Nature 358, 2; 1992) regarding the use of English in scientific publications. Having published a news item in which "bacillus thuringiensis (Bt)" [lower case for the genus name, no italics for the abbreviation] is described as "a bacteria" (Nature 355, 661 ; 1992) Nature is in no position to put itself on a pedestal as the guardian of those standards.

John B. Carter

School of Biomolecular Sciences,

Liverpool Polytechnic,

Byrom Street,

Liverpool L3 3AF, UK

\section{Dam facts}

SIR - You say (Nature 356, 363; 1992), "Who but the US Army Corps of Engineers built Boulder Dam?"

The answer is that it was constructed by the Six Companies, Inc. for the US Bureau of Reclamation, which engineered it and owns it.

\section{Bryant Mather}

Department of the Army,

Waterways Experiment Station,

Corps of Engineers,

3909 Halls Ferry Road,

Vicksburg,

Mississippi 39180-6199, USA

NATURE • VOL 358 • 20AUGUST 1992 